\title{
Paulus i Aarhus - fra Johannes Munck til nu ${ }^{1}$
}

\author{
Professor, Dr. theol. habil. \\ Eve-Marie Becker
}

\begin{abstract}
Recapitulating Johannes Munck's most prominent international contribution to the field of Pauline exegesis, this article at the same time reflects upon the history of New Testament studies in Aarhus: from the time of Munck's employment as professor of New Testament exegesis in 1938 to the founding of the Faculty of Theology in 1942 and up to his early death in 1965 as well as even more recent times. Munck's interest in and view on Paul, however, not only provide insight into the history of Theology at Aarhus University: theycan also be seen as an eminent paradigm of New Testament research history, the reception of Paul, and questions about methods and hermeneutics in particular, shortly before, during, and soon after World War II.
\end{abstract}

Keywords: Paul - Pauline research - Acts of the Apostles - salvation history - history of theology - Johannes Munck

\section{Tilbageblik: Analoge spørgsmål i historiens løb}

Kort før slutningen af sit ophold som Visiting Professor ved Princeton Theological Seminary, hvor Johannes Munck i det akademiske år 1964-1965 afholdt en forelæsningsrække over Apostlenes Gerninger, måtte den danske professor i februar 1965 ganske pludseligt forlade USA på grund af sygdom og vende hjem til Danmark. Kun 12 dage senere døde han i Aarhus "peacefully," som hans hustru Elisabeth skrev $\mathrm{i}$ indledningen til Muncks posthume, engelsksprogede kommentar til Apostlenes Gerninger, The Acts of the Apostles. ${ }^{2}$

Arbejdet med kommentaren til Lukas' værk om apostlene-Muncks eneste nytestamentlige kommentar - hører sammen med en "major address" ved møde nummer 100 i Society of Biblical Literature (New York, 28.-30. december 1964), hvori Munck ganske programmatisk

1. Jeg takker min kollega, lektor emeritus Helge Kjær Nielsen for værdifulde henvisninger i mit manuskript. Artiklen er oversat fra tysk af ph.d.-studerende Mattias Skat Sommer.

2. AncB 31 (Garden City, NY: Doubleday 1967), VIII. Den danske udgave Apostlenes gerninger var udkommet i 1964. 
reflekterer over "Pauline Research since Schweitzer,"3 til dennes akademiske ultima verba. Begge er så at sige testamentariske arbejder, og begge stammer fra Muncks tid i Amerika. Således slutter der sig på flere måder en cirkel om hans forskerliv: Munck, der kom fra patristikken, fokuserede fra og med de sene 1940'ere, helt præcist fra 1947, mere og mere på Paulus og Paulusbrevene, og udforskede således kristendommens begyndelse. I den forbindelse rettede han også sin opmærksomhed indgående mod Apostlenes Gerninger.

Munck tilhørte, så vidt jeg kan se, ingen skole og intet forskernetværk. Akademisk betragtet bevægede han sig ubesværet af kontinentale bindinger. I sit arbejde stræbte Munck efter at spørge kritisk ind til de "dogmatic formula," som indsnævrede studiet af Paulus og den tidligste kristendom, samt at udfordre holdningerne blandt de forskere og præster, for hvem Paulus var "unpopular," og som forstod sig selv som en "personal enemy of Paul" (Munck 1965, 167f.). Munck så det som en opgave for den nytestamentlige forskning at tilbyde hjælp til kirker over hele verden med deres spørgsmål og udfordringer (jf. ibid., 174). Det tidsforskudte, lukanske blik på Paulus' virke, som kendetegner Apostlenes Gerninger, er på sin vis en del af Paulusforskeren Muncks eksegetiske testamente. Muncks lukanske Paulusfortolkning og hans tilbageblik på Paulusforskningen sætter os i stand til retrospektivt at belyse hans forskningsinteresse i Paulus og det paulinske apostolat, som begge er grundtemaer i hans eksegetiske arbejde fra tiden som professor i Aarhus.

Hvilket syn på forskningshistoriens Paulus og på den lukanske Paulus udarbejder Munck så i sin SBL-address og i sin kommentar? I indledningen til kommentaren beskriver Munck med emfatiske ord den teologiske og personlige motivation, der må have drevet historikeren Lukas i dennes komposition af Apostlenes Gerninger. Munck påpeger, at skriftets portræt af Paulus:

... is not the portrait of a saint or of a bloodless ideal, but a portrait so striking and convincing that it seems to be drawn from life. One who could so describe Paul must have known him intimately and loved him (Munck 1967, XXXV).

Munck forstår først og fremmest Lukas som "witness, not as an advocate" for Paulus (ibid., LXXXIV), ligesom han i øvrigt søger at fremstille den tidligste kristendom som en gruppe præget af intern

3. Johannes Munck, "Pauline Research since Schweitzer", The Bible in Modern Scholarship: Papers read at the $100^{\text {th }}$ Meeting of the Society of Biblical Literature. December 28-30, 1964, red. J. P. Hyatt (Nashville, KY/New York: Abingdon Press 1965), 166-177. 
enighed snarere en af divergerende meninger. ${ }^{4}$ Munck daterer affattelsestidspunktet for Apostlenes Gerninger til de tidlige 60'ere under henvisning til den åbne slutning og den manglende reference til en allerede foreliggende samling af Paulus' breve (Munck 1967, XLVILIV). Således læser Munck Apostlenes Gerninger som et katalog over de spørgsmål og diskussioner, som endnu plagede "primitive (Jewish) Christianity” før år 70 e.Kr. (jf. ibid., LXIIff.). I det hele taget vil Munck undgå, at det $\mathrm{Ny}$ Testamente opdeles i "watertight compartments", som om "there was no connection between the different parts" (Munck 1965, 169).

Munck var i løbende diskussion med Ferdinand C. Baur og det 19. århundredes Tübingerskole (jf. endvidere Munck 1965, 168f.), som søgte at gøre den religionshistoriske forskel på jøde- og hedningekristendom gældende allerede fra kristendommens begyndelse hos Paulus og i Apostlenes Gerninger, og han kritiserede til stadighed sin samtids liberale teologi for at have frembragt en byzantinistisk forskningsindstilling (jf. ibid., 172f.). Derfor handlede det for Munck i SBL-talen såvel som i kommentaren til Apostlenes Gerninger om at fremhæve de teologiske konvergenser i den tidligste kristendom: "What is needed for fruitful Pauline research is the work of placing the apostle in connection with Jesus, the twelve apostles and the church after his time" (Munck 1965, 167).

Munck betoner i kommentaren, at primitiv kristendom i de første generationer i det første århundrede e.Kr. i sit væsen må forstås som jødisk kristendom: "we mean the Christianity found in the first churches formed in Palestine by Jews believing in Christ" (Munck 1967, XXXI). På den ene side må denne "(Jewish) Christianity group" adskilles fra en "Judaizing movement, which was a heretical Christianity which sought to extend Christianity by requiring that Christians also be Jews who are circumcised and keep the law of Moses" (ibid., XXXI). Som en sådan judaiserende gruppe identificerer Munck for eksempel Paulus' modstandere i Galaterbrevet, der oprindeligt stammer fra et hedningekristent miljø: "Die judaistischen Gegner im Galaterbrief sind Heidenchristen." $\mathrm{Om}$ en hedningekristendom som sådan kan man $p a ̊$ den anden side først tale i det andet århundrede: "As far as primitive Christianity is concerned 'Gentile Christianity' posits something which never existed outside the thought of the Tübingen School" (Munck 1967, XXXII). I overensstemmelse hermed vil Munck finde forfatteren til Apostlenes Gerninger, Lukas, "among

4. Jf. allerede "Menigheden uden Partier", DTT 15 (1952), 215-233.

5. Johannes Munck, Paulus und die Heilsgeschichte, Acta Jutlandica 6 (København: Munksgaard, 1954), 79. 
Paul's fellow workers [...] whether they were Jew or Gentile by birth" (ibid., XXXII).

Allerede i sin presidential address som formand for Studiorum Novi Testamenti Societas fra 1959 havde Munck udarbejdet lignende distinktioner for historisk at opridse "Jewish Christianity in Post-Apostolic Times". ${ }^{6}$ Her adskiller han kronologisk frem for alt en primitiv jødisk kristendom, som må lokaliseres til Jerusalem og som efter år 70 e.Kr. ikke længere eksisterede, fra en "post-apostolic Gentile Church," som var "Jewish-Christian [...] in the sense that its founders were Jewish-Christian apostles such as Paul" (Munck 1959, 114, citaterne oprindeligt kursiverede). Definitionen af "Jewish Christianity" baserer sig altså i det væsentlige på den religiøse identitetsbeskrivelse hos dens ledere. Således sammenfatter kommentaren til Apostlenes Gerninger, om end den ikke fuldendtes af forfatteren, i adskillige henseender det, hvormed Munck i løbet af sin tid som professor i nytestamentlig eksegese ved Aarhus Universitet gennem næsten 30 år (fra 1938 til 1965) var beskæftiget: Med udforskningen af de (apostolats)teologiske og missionshistoriske begyndelser på kristendommen.

Indtil nu skulle nogle aspekter af den analogi gerne være tydeliggjort, som gav tilskyndelsen til nærværende bidrag, der skal betænke og påskønne 75 års historie med universitetsteologi i Aarhus: Ligesom Paulus må regnes blandt den tidligste kristendoms grundlæggelsesfigurer, må Johannes Munck anses som en af stifterne af teologi ved Aarhus Universitet i 1942. Vi skal i det følgende ikke in extenso udgranske, men snarere i tre korte skridt antyde og udfolde denne analogi mellem grundlæggelsen af teologistudiet ved universitetet i februar 1942 og den i netop disse år voksende interesse hos Munck for det paulinske apostolat: Et kort blik på Muncks faglige udvikling tjener til at klargøre hans betydning for først teologien og den nytestamentlige forskning i Aarhus, og dernæst også for den internationale nytestamentlige forskning. Afslutningsvis skal det skitseres, hvilken rolle den Paulusforskning, der blev igangsat af Munck, kan tilkendes i nutiden, både i og uden for Aarhus.

\section{Johannes Muncks vej til Paulus}

Johannes Munck blev født i København den 3. marts 1904. Videnskabshistorisk og -politisk hører han til de prægende skikkelser

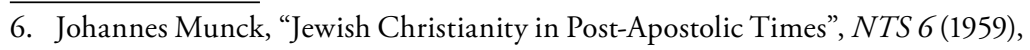
103-116. 
i dansk universitetshistorie i det tyvende århundrede og personificerer derved den moderne lærde, som bevidst udøver sin forskning og undervisning i konkrete verdens- og universitetspolitisk prægede situationer. Muncks omfattende nationale så vel som internationale betydning som forsker, teolog og universitetsprofessor bliver tydelig, når man betragter de forskellige funktioner, han udøvede inden for den nytestamentlige forskning, teologien i Danmark og særligt universitetspolitikken i Aarhus: Således var Munck den første dekan for det Teologiske Fakultet ved dets grundlæggelse midt under Anden Verdenskrig den 4. februar 1942. Fra 1943-1945 beklædte Munck embedet som rektor for Aarhus Universitet i en ekstraordinært svær verdenspolitisk situation: Årene under den tyske besættelse af Danmark og de dermed forbundne udfordringer for forskning, undervisning og universitetsledelse beskriver Munck indgående kort efter krigen. ${ }^{7}$ Munck var medlem af universitets konsistorium fra 1942-1962. Fra 1952 til 1955 var han præsident for Det Larde Selskab i Aarhus. Munck fungerede 1959 til 1960 som formand for Studiorum Novi Testamenti Societas og var leder af SNTS-konferencen i Aarhus i 1960. Derudover var Munck medredaktør af Dansk Teologisk Tidsskrift fra 1946 til 1961, stifter og formand for Teologisk Forening fra 1939 til 1949 samt af Collegium Biblicum 1947 til 1960. Munck modtog æresdoktorgrader ved universiteterne i Oslo (1961) og Glasgow (1962) og blev 1946 og 1954 tildelt henholdsvis ridderkorset samt ridderkorset af første grad af Dannebrogordenen.

I det følgende skal vi dog ikke fortsætte med at fremstille og hylde Muncks udvikling og fortjenester i detaljer - talrige nekrologer og levnedsbeskrivelser gør dette mere udførligt og grundigt, end vi ville kunne her. ${ }^{8}$ Snarere vil vi spørge ind til, hvornàr og hvordan Munck blev til Paulusforsker og dermed definerede sin rolle som professor i nytestamentlig eksegese i Aarhus. Sit første bidrag til Paulusforskningen offentliggjorde Munck i 1947. ${ }^{9}$ Allerede her bliver den spørgehorisont tydelig, inden for hvilken Munck udfoldede sine Paulusstudier: Det paulinske apostolat i relation til Israels frelseshistorie.

I deres nekrolog over Munck redegør Erling Hammershaimb (19041994) og Bent Noack (1915-2004) inden for rammerne af den aarhu-

7. Jf. "Aarhus Universitet under Besættelsen", Aarhus under Besattelsen, red. G. Andrésen (1946), 143-158; "Aarhus Universitet”, De fem lange År, red. J. Brøndsted/K. Gedde (1947), 1176-1188.

8. Jf. fx "Munck, Johannes, 1904-1965", ST 19, 1-2 (1965), 1-2; J. V. Andersen, "Bibliographie de l'oeuvre de Johannes Munck", ST 19, 1-2 (1965), 3-21; R. Bring, "Johannes Munck in Memoriam", STK 41 (1965), 63-64; B. Noack, "Johannes Munck, exeget og teolog", DTT 35 (1972), 126-134.

9. “Nogle Bemærkninger til Paulus' Kaldelse ved Damaskus", Festskrift til J. Nørregaard (København: G.E.C. Gads Forlag 1947), 186-202. 
sianske universitetshistorie for, hvordan Munck først efter krigs- og besættelsesårene påbegyndte arbejdet med sit egentlige forskningstema, "hvis emne skulle være apostolatet i Det nye Testamente som baggrund for en ny behandling af kristendommens tilblivelseshistorie." Med til denne sammenhæng hører også Muncks i første omgang $p a-$ tristisk orienterede forskningsinteresse i Paulus: "Som kyndig historiker og filolog tog han sit naturlige udgangspunkt i de ældste kilder, Paulus' breve" (ibid., 11). Som historiker ville Munck - i en såvel konstruktiv som kritisk diskussion med Adolf von Harnack - udforske de missionshistoriske begyndelser på kristendommen. ${ }^{11}$ Israels forhold til hedningerne ("Heiden", "gentiles") spillede en afgørende rolle for Muncks blik tilbage på kristendommens begyndelser. ${ }^{12}$ Han identificerede, fuldstændigt korrekt, Paulusbrevene som de ældste, bevarede kilder til netop dette forskningsfelt. Enhver historisering af den tidligste kristendom måtte ifølge Munck tage sit udgangspunkt hos Paulus.

Denne indsigt formede sig som resultat af Muncks historiske og filologiske arbejde gennem sit forskerliv, for i begyndelsen lå hans interesse inden for det patristiske forskningsområde. Denne forskningsinteresse var blevet vakt i hans studietid i København. Her havde kirkehistorikeren Jens Nørregaard (1887-1953), hvem Munck senere tilegnede studien Paulus und die Heilsgeschichte (Munck 1954), stor virkning på den unge student, og Nørregaard animerede ham til at forfatte sin disputats om Klemens fra Alexandria (Untersuchungen über Klemens von Alexandria, 1933). Spørgsmålet er, hvordan Johannes Muncks senere forskningsinteresse i kristendommens begyndelser og særligt Paulus og Apostlenes Gerninger lader sig forklare - en interesse, der voksede frem i Aarhus efter Anden Verdenskrig, og som derfor ret præcist kan dateres til årene fra 1947 og frem.

Mit indtryk er, at Munck - trods den tidlige faglige og tematiske prægning fra den københavnske nytestamentler Frederik Torm (1870-1953), som burde undersøges særskilt - med sine i udpræget grad filologiske og historiske interesser kom til at forstå sin undervisnings- og forskningsopgave i overensstemmelse med stillingsopslaget, der offentliggjordes i Statstidende den 13. oktober 1938: "Professorat i nytestamentlig eksegese." Studiet af Paulus rykkede i centrum for både Muncks egen forskningsinteresse og for hans samarbejde med sine studerende, til hvem han ville formidle Pauluseksegese. Denne

10. “Johannes Munck, 3. marts 1904 - 22. februar 1965", http://www.au.dk/fileadmin/www.au.dk/universitetshistorisk_udvalg/filer/Person_-_Munck__Johannes_-_nekrolog, 11 (besøgt 09.08.2017).

11. Jf. fx “Den ældste Kristendom i Apostlenes Gerninger”, DTT 16 (1953), 129164.

12. Jf. fx “Israel og Hedningerne i det Ny Testamente”, DTT 14 (1951), 65-81. 
interesse blev allerede tydelig i de første år af professoratet (19381942) og dermed altså før den faktiske grundlæggelse af det Teologiske Fakultet. ${ }^{13}$ Men interessen kunne øjensynligt først efter færdiggørelsen af rektoratsopgaverne i 1945 i en verdenspolitisk kompliceret situation udarbejdes grundigere i Muncks eksegetiske forskning.

\section{Den internationale betydning af den munckske Paulusforskning}

Retrospektivt bliver det tydeligt, at Johannes Munck i adskillige henseender var langt forud for sin samtids Paulusforskning. Allerede i hans eksegetiske studier fra de sene 1940'ere og tidlige 1950 'ere, der for størstedelens vedkommende var blevet til på baggrund af gæsteforelæsninger i Lund, Oxford eller Oslo, og som først blev publiceret som tidsskriftsartikler, udviklede Munck grundperspektiverne for det, der senere - knyttet til navne som Krister Stendahl, ${ }^{14}$ Ed P. Sanders og James D.G. Dunn - gjorde sit indtog som et såkaldt "new perspective" i Pauluseksegesen og bevirkede et paradigmeskifte. ${ }^{15}$ Disse studier af Munck har produktive eftervirkninger helt op i nutiden. ${ }^{16}$

Ifølge Munck må Paulus som jøde forstås i sammenhæng med Jerusalem og som en del af den jerusalemitiske jødekristendom. ${ }^{17}$ Paulus' mission blandt hedninger drejer sig først og sidst om Israels frelse: "For Christianity had its origin in Judaism, and it is Jesus who recreated Israel's religion in the form in which it became a religion of Gentiles all over the world" (Munck 1955, 174f; jf. Munck 1965, 175). Samtidigt betoner Munck, at kristendommen fra begyndelsen havde en særegen karakter: "The NT material shows us that Christianity was something new from the start” (Munck 1955, 175).

13. Jf. fx "Paulus skal læres i Studiekredse", Aarhus Stiftstidende (27/7 1941); "Paulus fik ny Kraft gennem sin Afmagt", Aarhus Stiftstidende (17/10 1943).

14. Jf. endvidere K. Stendahls forord til Christ \& Israel: An Interpretation of Romans 9-11 af Johannes Munck. Oversat af Ingeborg Nixon (Philadelphia, PA: Fortress 1967).

15. Jf. J. Frey, "The Jewishness of Paul”, O. Wischmeyer (red.), Paul: Life, Settings, Work, Letters (London/New York: Continuum 2012), 57-95.

16. Jf. fx, R. Last, "What Purpose Did Paul Understand His Mission to Serve?", HThR 104 (2011), 299-324; L. J. Windsor, Paul and the Vocation of Israel: How Paul's Jewish Identity Informs his Apostolic Ministry, with Special Reference to Romans, BZNW 205 (Berlin/Boston, MA: Walter de Gruyter 2014), 26-27: "For Munck, Paul stood as the pivotal, climactic position in the line of key Old Testament figures in God's plan of salvation" (27); Munck "sees Paul as a thoroughly Jewish figure" (27).

17. Jf. "Paulus og Jerusalem”, DTT 18 (1955), 20-44. 
Det her skitserede munckske syn på Paulus og den tidligste kristendom må for det forste forstås som en eksplicit kritisk refleksion over de forskningsparadigmer i på den ene side det 19. århundredes historieopfattelse og på den anden side den liberale teologi, der var fremherskende helt op i Muncks egen tid: Munck øver i nærved alle sine bidrag til Paulusforskningen en tydelig kritik af Ferdinand Chr. Baur og Tübingerskolen (Munck 1954, 61ff.; 79ff.), som også gør sig gældende i hans kommentar til Apostlenes Gerninger. Selvom Tübingerskolens litteraturhistoriske hypoteser nok har mistet betydning i det 20. århundrede, genfinder Munck i sin samtids nytestamentlige forskning den af Baur konstruerede problematiske modsætning "mellem Paulus og Urmenigheden [...] Man antager, at Jødekristendom og Hedningekristendom stod hinanden imod [...] Billedet af Paulus bliver derfor et Billede af en ensom Apostel" (Munck 1952, 215).

Munck forstår desuden sig selv i kritisk opgør med kirkehistorikeren Karl Holl, som han kendetegner som "en fremragende historiker, men ikke nogen god ekseget" (Munck 1955, 25), men også med den såkaldt liberale teologi, sådan som den fremlægges i Adolf von Harnacks "Mission und Ausbreitung des Christentums in den ersten drei Jahrhunderten." ${ }^{18}$ Munck stiller sig også kritisk over for Adolf Deissmann og dennes udtalte interesse i Paulus' person. ${ }^{19}$ I denne sammenhæng skal man nok også forstå Muncks kritik af enhver psykologisk tolkning af Paulus (Munck 1954, 3; 15ff.), som i en vis forstand foregriber Stendahls virkningsfulde bidrag fra årene 1962-1963, der sigtede mod at dekonstruere den psykologiske og eksistentielle Paulusfortolkning, som var fremherskende i den lutherske Paulusopfattelse til og med Rudolf Bultmann. ${ }^{20}$ Slutteligt viser Johannes Munck sig også kritisk over for Martin Dibelius og stiller sig tvivlende over for dennes syn på Apostlenes Gerninger, der alene er præget af stilkritisk analyse og ikke lader skriftets traditionsindhold falde inden for synsvinklen (jf. Munck 1965, 171).

For det andet må Muncks Paulusbillede forstås på baggrund af de specifikke forskningsinteresser, som førte den aarhusianske forsker tilbage til kristendommens begyndelse: På den ene side gør Munck det Paulinske apostolat til sit forskningstema (jf. Munck: 1954, 1-60; 162169) - et tema, som han endda sætter i forbindelse med sin udlægning

18. Jf. Johannes Munck, "Israel and the Gentiles in the New Testament", JTS 2

(1951), 4.

19. Johannes Munck, "I Thess. I.9-10 and the Missionary Preaching of Paul:

Textual Exegesis and Hermeneutic Reflexions", NTS 9 (1962-63), 95.

20. K. Stendahl, "The Apostle Paul and the Introspective Conscience of the West", Journal for the Scientific Study of Religion 1/2 (1962), 261-263; idem, "The Apostle Paul and the Introspective Conscience of the West”, HTR 56 (1963), 199-215. 
af Åb 11. ${ }^{21}$ Muncks Paulusbillede er delvist præget af antagelsen af autenticiteten i 2 Thess (jf. Munck 1951, 7). På den anden side vælger Munck undersøgelsen af Israels forhold til hedningerne som sit tematiske fokus. Dette fokus fører til, at Munck i missionshistorisk henseende undersøger kategorierne "universalisme" og "partikularisme" ikke blot hos Paulus, men også i evangelierne og tilbagesporer deres mulige oprindelse til Jesu forkyndelse. ${ }^{22}$ Som resultat heraf forekommer Paulus ikke at være en mulig antipode til, men snarere den kongeniale fortolker af Jesu forkyndelse. Det er i sammenhæng hermed, at man skal betragte Muncks udlægning af Rom 9-11 i Christus und Israel: eine Auslegung von Röm 9-1123, som Munck tilbageskuende beskriver som det væsentligste forarbejde til studien "Paulus und die Heilsgeschichte" udarbejdet mellem 1949 og 1952 (jf. forordet i Christus und Israel). Den teologiske udfordring, Paulus står foran i Romerbrevet, ser Munck i hovedsagen begrundet i "Israels Unglaube" (ibid., s. 19ff.). I den senere tekst "Pauline Research since Schweitzer" hævder Munck en lignende pointe: "It was the unbelief of the Jews that altered the course of Christianity" (Munck 1965, 175).

Den teologihistoriske indplacering af Johannes Munck er vanskelig. Mod slutningen af sin SNTS presidential address giver Munck klart udtryk for sin akademiske holdning. Her fremlægger han i programmatiske ord, hvorledes han forstår den nytestamentlige forskningsopgave:

Let us give the younger generation opportunity and encouragement to question the important, but perhaps not always true or permanently valid views put forward by the generation before us. Let us go further, and urge them to question what we ourselves tell them" (Munck 1959, 115f.).

Bent Noack beskriver Munck som "kritisk konservativ. Han var en svoren modstander af ubeviste hypoteser [...] Det var ham altid om at gøre at komme fri af stereotype problemstillinger og at se på problemerne med egne øjne” (Noack 1972, 128). I sidste ende forstår vi derfor Johannes Muncks Paulusforskning bedst, når vi i den erkender et forsøg på kritisk at sætte spørgsmålstegn ved dominerende teologiske forskningspositioner ved hjælp af grundigt og selvstændigt filologisk arbejde. Munck frygtede, at udforskningen af den tidligste

21. Johannes Munck, Petrus und Paulus in der Offenbarung Johannis: Ein Beitrag zur Auslegung der Apokalypse (København: Rosenkilde og Bagger, 1950).

22. Johannes Munck, Christus und Israel: eine Auslegung von Röm 9-11, Acta Jutlandica 7 (København: Munksgaard 1956), især 21-24.

23. Jf. note 14 .. 
kristendom gennem brug af historiske og hermeneutiske paradigmer udelukkende ville producere fastlåste eller endda fastkørte indsigter. Som central spørgehorisont for sin kritiske revision valgte Munck det paulinske apostolats stilling og betydning i forhold til Jerusalem og Israels frelseshistorie. I dette perspektiv forekommer Paulus ikke længere at handle isoleret eller at være en "ensom" apostel, og forskellen mellem henholdsvis paulinsk og jerusalemitisk mission bliver - helt i overensstemmelse med historikeren Lukas - overvundet.

\section{Udblik: Paulus i Aarhus fra 1938/1942 til 2017}

Paulusforskningen udgør et stort og vidtstrakt område inden for nytestamentlig forskning. De tematiske og metodiske impulser, som Johannes Munck berigede forskningen med, påskønnes til stadighed både $\mathrm{i}$ og uden for Aarhus. At den nytestamentlige forskergruppe $\mathrm{i}$ Aarhus i 2012 etablerede en årlig "Johannes Munck Lecture" tager højde for ønsket om at erindre og påskønne Muncks betydningsfulde arbejde. $^{24}$

Som antydet ovenfor har Munck frem for alt muliggjort nye vigtige religionshistoriske sporskifter i bestemmelsen af Paulus' forhold til jødedommen. Samtidig beklager Munck konservatismen i sin samtids nytestamentlige forskning, som er betinget af en "confusion between philosophical und systematic theological ideas and historical facts" (Munck 1965, 172). Muncks eksegetiske og historiske betragtninger, antagelser eller indsigter kan og skal gøres til genstand for kritisk diskussion og vurdering. Det gælder fx hans datering af Apostlenes Gerninger og autenticiteten af 2 Thess, hans karakteristik af jødedommen og jødisk kristendom samt af det universalistiske syn på den historiske Jesus, der faktisk indebærer en tidlig datering af den såkaldte Parting of the Ways. Men Muncks videnskabelige grundspørgsmål og overbevisninger er af blivende betydning. Det gælder blandt andet den videnskabelige interesse i disciplinoverskridende problemstillinger - den nytestamentlige eksegese lever især af den vitale dialog med patristikken, med den gammeltestamentlige og med den judaistiske forskning - såvel som den sunde tvivl på stereotypiske eller ideologisk drevne forskningsparadigmer, der indsnævrer Pauluseksegesen frem for produktivt at videreudvikle den. Først denne videnskabelige tvivl gør et ansvarligt og selvstændigt eksegetisk arbejde muligt. I bedømmelsen af den munckske arv og af begyndelsen på Paulusforskningen

24. Jf.: http://nt.au.dk/johannes-munck-lectures/ (besøgt 09.08.2017). 
i Aarhus handler det mindre om i detaljer at dele Muncks syn på det første århundrede og mere om at dele forskerens kritiske "spirit" (således Munck selv i Munck 1965, 173).

Med til den blivende arv for den munckske historie- og teologiopfattelse i Aarhus hører desuden den indsigt, at den historiske Jesusforskning må forbindes med Paulusforskningen og med den tidligste kristendoms historie (jf. Munck 1965, 167), samt at kristendommens historie i det første århundrede kun kan rekonstrueres og skrives med og om Paulus og Paulusbrevene som de ældste kilder. Til trods for ethvert kildearbejde, der rækker ud over den nytestamentlige kanon, består den nytestamentlig eksegeses primære opgave ifølge Munck i "to read and study the NT as a whole" (Munck 1965, 169). Muncks arbejde om og med Paulus tager eksegetisk, dvs. historisk og filologisk, derfor altid udgangspunkt i de nytestamentlige tekster selv og præges gennemgående af en vis metodisk begrænsning til Paulus' formodede 'hovedbreve' (Rom, Gal, 1 og 2 Kor).

Munck kan fungere som forbillede for nutidig Paulusforskning både i og ud over Aarhus, fordi han er bevidst om den kirkelige og samfundsmæssige betydning af en saglig beskæftigelse med Paulus (jf. Munck 1965, 168) og endda beskriver dette som en udfordring med konsekvenser for det europæiske kontinent. ${ }^{25}$ Fra min - nu omtrent tiårige - undervisningserfaring i Aarhus kan jeg kun tilslutte mig Muncks bestræbelse på at italesætte de (negative) fordomme om Paulus, der findes i både kirke og samfund. Ligeledes har jeg ofte erfaret, hvordan især den nytestamentlige introduktion til Paulus på teologistudiet - indtil nu „NT III“ - som intet andet nytestamentligt fag har indført de studerende i ikke bare de metodiske, men også de hermeneutiske og teologiske grundspørgsmål i den nytestamentlige forskning og netop herved har begejstret dem. Munck spidsformulerer denne social- og kirkepolitiske relevans ved Paulusforskningen:

Not only as scholars is it our task to renew our scholarship, but for the church and its members it is of importance that we interpret the Bible for men and women of today, and thus not remain hindered by obsolete philosophical and theological doctrines (Munck 1965, 174).

"Paulus i Aarhus" - det foreliggende bidrag tager mange spørgsmål op, som i grunden fører langt ud over Johannes Munck. Hans livsværk inspirerer til adskillige analogidannelser. Jeg formoder, at Munck selv ville have sat pris på denne problematik, eftersom han i 1950 til Berlingske Tidende skrev et ganske vist temmelig populærvi-

25. Johannes Munck, "Paulus i Europa", Berlingske Tidende (9/3 1950). 
denskabeligt bidrag med den programmatiske titel: "Paulus i Europa" (9/3 1950). For at markere de 1900 år for Paulus' påbegyndelse af sin missionsvirksomhed i Europa udtrykker Munck heri sit håb om, at Europa også for fremtiden husker på den kulturelle prægning, der udgik fra den paulinske mission. Intet andet spørgsmål synes i dag mere vigtigt og påtrængende, når det gælder om kritisk at diskutere og videretænke den nytestamentlige forskning såvel som teologiens selvforståelse: Dette gælder for Aarhus, Danmark, Europa, ja for kristendommen verden over.

\section{Johannes Muncks studier i Paulus og jødekristendommen $(1947-1967)^{26}$}

\section{Monografier}

Munck, Johannes. Petrus und Paulus in der Offenbarung Johannis: Ein Beitrag zur Auslegung der Apokalypse. Det Lærde Selskab i Aarhus Teologiske Skrifter 1. København: Rosenkilde og Bagger, 1950.

Munck, Johannes. Paulus und die Heilsgeschichte. Acta Jutlandica 6. Aarhus: Universitetsforlaget, København: Munksgaard, 1954.

Munck, Johannes. Paul and the Salvation of Mankind. Oversat af Frank Clarke. Richmond, VA: John Knox, 1959.

Munck, Johannes. Christus und Israel: eine Auslegung von Röm 9-11. Acta Jutlandica 7. Aarhus: Universitetsforlaget, København: Munksgaard, 1956.

Munck, Johannes. Christ \& Israel: An Interpretation of Romans 9-11. Oversat af Ingeborg Nixon. Philadelphia, PA: Fortress, 1967.

Munck, Johannes/Pedersen, Sigfred. Apostlenes gerninger $i$ dansk oversattelse med noter. Acta Jutlandica 36,2, Teologisk Serie 9. Aarhus: Universitetsforlaget, København: Munksgaard, 1964.

Munck, Johannes. The Acts of the Apostles. AncB 31. Garden City, NY: Doubleday, 1967.

Bidrag til tidsskrifter, festskrifter m.v.

Munck, Johannes. "Grønbechs trilogi om urkristendommen”, DTT 6 (1943), 29-49.

26. Jeg takker Brad Biggerstaff, MDiv-Student ved Candler School of Theology, Emory University, Atlanta, USA, for hans store hjælp ved litteraturfremskaffelsen og udarbejdelsen af den foreliggende bibliografi. 
Munck, Johannes. “Nogle Bemærkninger til Paulus' Kaldelse ved Damaskus”, Festskrift til J. Nørregaard, København: G.E.C. Gads Forlag, 1947, 186-202.

Munck, Johannes. "La vocation de l'apôtre Paul”, StTh 1 (1947-1948), 131-145.

Munck, Johannes. "Paulus' Apostolat og Apostelbegrebet i det Ny Testamente", DTT 11 (1948), 141-157.

Munck, Johannes. "Paul, the Apostles, and the Twelve", StTh 3 (1950), 96-110.

Munck, Johannes. "Israel og Hedningerne i det Ny Testamente", DTT 14 (1951), 65-81.

Munck, Johannes. "Israel and the Gentiles in the New Testament", SNTS Bulletin (1950), 26-38.

Munck, Johannes. "Israel and the Gentiles in the New Testament", JTS 2 (1951), 3-16.

Munck, Johannes. "Hat das Judentum den Namen YOU (Jehu) gebraucht?", StTh 5 (1952), 167-172.

Munck, Johannes. "Menigheden uden Partier: Studier over 1 Kor 1-4", DTT 15 (1952), 215-233.

Munck, Johannes. "Den ældste Kristendom i Apostlenes Gerninger”, DTT 16 (1953), 129-164.

Munck, Johannes. "Paulus og Jerusalem”, DTT 18 (1955), 20-44.

Munck, Johannes. "Paulus for Kejseren”, DTT 18 (1955), 65-85.

Munck, Johannes. Art. "Paulus”, Nordisk Teologisk Leksikon 3 (1957), 36-44.

Munck, Johannes. "Jewish Christianity in Post-Apostolic Times", NTS 6 (1959), 103-116.

Munck, Johannes. “Jødekristendommen efter apostlenes dage”, DTT 22 (1959), 103-116.

Munck, Johannes. "Judenkristendomen efter apostlarnas dagar”, SEA 25 (1960), 78-96.

Munck, Johannes. “New Testament and Gnosticism”, StTh 15 (1961), 181195.

Munck, Johannes. "I Thess. I.9-10 and the Missionary Preaching of Paul: Textual Exegesis and Hermeneutic Reflexions”, NTS 9 (1962-63), 95110.

Munck, Johannes. "Primitive Jewish Christianity and Later Jewish Christianity: Continuation or Rupture?", Aspects du Judéo-Christianisme. Colloque de Strasbourg 23-25 avril 1964, Paris: P. U. F., 77-91.

Munck, Johannes. "Pauline Research since Schweitzer", The Bible in Modern Scholarship: Papers read at the $100^{\text {th }}$ Meeting of the Society of Biblical Literature. December 28-30, 1964, red. J. P. Hyatt, Nashville, KYI New York: Abingdon Press, 1965, 166-177. 